\section{Endocardite valvular e mural em caprino - relato de caso}

\author{
Valvular and mural endocarditis in a goat - a case report
}

\author{
Cristiane da Rosa Moraes', Milene Dick², Saulo Petinatti Pavarini ${ }^{3}$, David Driemeier ${ }^{3}$ \& Verônica Schmidt ${ }^{3 *}$ \\ 'Médica veterinária, Professora. Faculdade de Veterinária, Centro Universitário Ritter dos Reis, Porto Alegre, RS, Brasil \\ 2Médica veterinária, Fiscal Agropecuário. Ministério da Agricultura, Pecuária e Abastecimento, Bagé, RS, Brasil \\ ${ }^{3}$ Médicos veterinários, Professores. Faculdade de Veterinária, Universidade Federal do Rio Grande do Sul - UFRGS, Porto \\ Alegre, RS, Brasil
}

\section{Resumo}

Endocardite é a inflamação do endocárdio. São classificadas, quanto à localização, em valvulares, se a lesão se assenta na válvula, e murais se a alteração se estabelece na parede endocárdica. com lesões, na forma mural, localizadas nas aurículas ou ventrículos e, na forma valvular, nas valvas. Relata-se um caso de endocardite em um caprino macho, da raça Boer, com um ano de idade. O caprino apresentou sinais clínicos respiratórios e perda de peso e, após tratamento com enrofloxacina e tetraciclina, não apresentou melhora e veio a óbito. Na necropsia, os rins estavam inchados, os pulmões estavam aderidos à pleura costal e havia presença de nódulos no saco pericárdio e coração. A histologia revelou pneumonia, hepatite e miocardite, com formação de abscessos, caracterizando septicemia. Arcanobacterium pyogenes foi identificado a partir de amostras de pulmões, fígado e sangue. Embora geralmente associado a infecções localizadas, este relato destaca a possibilidade do envolvimento de $A$. pyogenes em quadro septicêmico decorrente de endocardite em caprino.

Palavras-chave: caprino, endocardite, Arcanobacterium pyogenes.

\begin{abstract}
Endocarditis is the inflammation of the endocardial lining. Endocarditis may be mural, when the lesions are located on the lining of an auricle or ventricle, but it is much more frequently valvular, the lesions being located on the valves. The current study aims at reporting an endocarditis case of an 1-year-old male Boer goat, which had been showing clinical respiratory signs and weight loss. The treatment with enrofloxacin and tetracycline do not have result and the goat died. At necropsy, its kidneys were swollen, the lungs were adhered to the costal pleura and there were nodules on the pericardial sac and heart. Histology revealed pneumonia, hepatitis and myocarditis with formation of abscesses, thus characterizing septicemia. Arcanobacterium pyogenes was identified from lungs, liver and blood samples. Although A. pyogenes is usually associated with localized infections, this report highlights the possibility of its involvement in the septicemia due to endocarditis disease in goats.
\end{abstract}

Keywords: goat, endocarditis, Arcanobacterium pyogenes.

\section{Introdução}

O rebanho mundial caprino cresceu cerca de 40\% em 20 anos (Brasil, 2010). Entretanto, a nível nacional este crescimento foi pouco mais de 10\% quando o efetivo caprino de oito milhões de cabeças em 1980, superou os nove milhões de cabeças em 2010 (Instituto Brasileiro de Geografia e Estatísitica, 2006, 2010). O maior efetivo de caprinos encontra-se no Nordeste e o Rio Grande do Sul possui 1,1\% do rebanho nacional (Instituto Brasileiro de Geografia e Estatísitica, 2010). Embora a produção de carne caprina mundial tenha aumentado mais de 80\% em 20 anos, o mesmo não foi observado no Brasil devido ao direcionamento da produção caprina para raças leiteiras e ao menor nível tecnológico utilizado pelos caprinocultores de corte (Brasil, 2010).

Com a introdução de mudanças no sistema produtivo, de extensivo para intensivo, aumentaram a incidência e gravidade das doenças que afetam o rebanho caprino (Rosa, 2012). O conhecimento das doenças dos animais domésticos, nas diferentes regiões do Brasil, éimportante para determinar formas eficientes de profilaxia e controle (Guedes et al., 2007), bem como sua divulgação permite que médicos veterinários de campo considerem estas enfermidades no diagnóstico diferencial de uma doença (Rosa, 2012).

\section{BJ M \\ Brazilian Journal of Veterinary Medicine \\ p-ISSN 0100-2430 \\ e-ISSN 2527-2179 \\ ○}

Como citar: Moraes, C. R., Dick, M., Pavarini, S. P. Driemeier, D., \& Schmidt, V. (2017). Endocardite valvular e mural em caprino - relato de caso. Brazilian Journal of Veterinary Medicine, 39(1), 68-73. doi: 10.29374/2527-2179.bjvm0242

Fonte de financiamento: Recursos próprios - UFRGS.

Conflito de interesses: Os autores declaram não haver conflito de interesses que precisam ser informados.

Recebido: Novembro 13, 2015.

Aceito: Julho 23, 2016.

O estudo foi realizado na Universidade Federal do Rio Grande do Sul - UFRGS, Porto Alegre, RS, Brasil.

\section{*Correspondência}

Verônica Schmidt

Faculdade de Veterinária, Universidade Federal do Rio Grande do Sul - UFRGS Av. Bento Gonçalves, 9090, Bairro Agronomia CEP 91540-000 - Porto Alegre (RS), Brasil E-mail: veronica.schmidt@ufrgs.br
Copyright Moraes et al. Este é um artigo publicado em acesso aberto (Open Access) sob a licença Creative Commons Attribution Non-Commercial, que permite uso, distribuiç̧ão e reprodução em qualquer meio, sem restrições desde que sem fins comerciais e que o trabalho original seja corretamente citado. 
Endocardite, em pequenos ruminantes, é mais comum em animais adultos e causada por infecção, alterações degenerativas, trauma, entre outras. As infecções crônicas ativas, como abcessos nas patas e no fígado, ruminite e onfaloflebite, podem causar bacteremia crônica ou recorrente que predispões o animal à endocardite bacteriana (Pugh, 2005). Esta é uma patologia provocada por uma infecção microbiana na superfície endotelial valvular e pode desencadear uma insuficiência cardíaca congestiva, com lesões em diversos órgãos, devido à liberação de êmbolos bacterianos.

Os sinais clínicos inespecíficos e a grande variedade de agentes implicados na etiologia desta doença, assim como a suscetibilidade aos antimicrobianos, fazem da endocardite um desafio para diagnóstico e tratamento em animais (Ventura \& Oliveira, 2011).

Entre os agentes de endocardite, Arcanobacterium pyogenes tem sido relatado em bovinos (Bianco et al., 2004). Esta bactéria, comensal e oportunista de diversas espécies de animais domésticos (Jost \& Billington, 2005) e silvestres, possui fatores de virulência que determinam resposta inflamatória intensa, além de vários processos infecciosos piogênicos. Em caprinos este microrganismo tem sido associado a casos de artrite, osteomielite, abortos, abscessos e mastite (Lavin et al., 1998; Moeller Junior, 2001; Contreras et al., 2003; Seifi et al., 2003; Barbour et al., 2010; Lin et al., 2010; Garino Junior et al., 2012).

O presente estudo relata um caso de endocardite mural e valvular por A. pyogenes em caprino, ocorrido no Rio Grande do Sul.

\section{Material e métodos}

Um caprino macho, raça Boer, com um ano de idade, oriundo do município de Viamão/RS, foi encaminhado ao setor de Patologia da Faculdade de Veterinária da UFRGS para diagnóstico pós mortem. Na anamnese foi relatado que o caprino apresentou quadro clínico de tosse e emagrecimento, com melhora clínica ao tratamento com oxitetraciclina. Após cinco dias, houve recidiva dos sinais clínicos e, desta vez, foi medicado com enrofloxacina e dipirona. Ainda no mesmo dia, o caprino apresentou insuficiência cardiorrespiratória aguda, com salivação e vocalização (gemidos) intensa, que culminaram com o óbito.

Realizou-se a necropsia do caprino sendo coletados fragmentos de diversos órgãos, mantidos em solução de formalina 10\%, processados rotineiramente para histologia e, posteriormente, os cortes foram corados pela técnica de hematoxilina e eosina (HE) (Thomson, 1983).

Amostras de pulmão, fígado e sangue, encaminhadas ao Laboratório de Medicina Veterinária Preventiva, da UFRGS foram semeadas em ágar acrescido de 5\% de sangue ovino eágar MacConkey e incubadas em aerobiose, a 370 C por 48 horas (Quinn et al., 2011).

\section{Resultados}

$\mathrm{Na}$ anamnese foi relatado que, ao exame clínico, o veterinário de campo encontrou sinais respiratórios (tosse e dispneia) compatíveis com pneumonia; sendo administrada oxitetraciclina e, posteriormente enrofloxacina no caprino. Entretanto, como o caprino não respondeu ao tratamento e apresentando a mesma sintomatologia clínica, foi iniciado tratamento com enrofloxacina.

À necropsia observaram-se pulmões com múltiplos pequenos nódulos amarelados com até 1,5cm de diâmetro além de aderências e pleura parietal. No coração, o endocárdio do ventrículo direito, septo interventricular e da valva átrio ventricular direita (tricúspide) estavam recobertos, em quase sua totalidade, por um material amarelado, irregular, de aspecto vegetante que se estendia para o miocárdio (Figura 1).

Microscopicamente, a lesão no coração era de endocardite mural e valvular, caracterizado por abundante deposição de fibrina associada a infiltrado de neutrófilos degenerados e miríades bacterianas na superfície do endocárdio (Figura 2), além de infiltrado moderado de linfócitos, plasmócitos e macrófagos no endocárdio e miocárdio adjacente. No pulmão, haviam abscessos multifocais, envoltos por uma fina camada de tecido conjuntivo, além de trombose multifocal com ocasionais estruturas bacterinas associadas.

Na pesquisa bacteriana, verificou-se crescimento bacteriano somente em ágar sangue, observando-se colônias com 1 a 2 mm de diâmetro, translúcidas e com uma estreita zona de $\beta$-hemólise. A coloração de Gram das colônias revelou bastonetes Gram-positivos pleomórficos. 


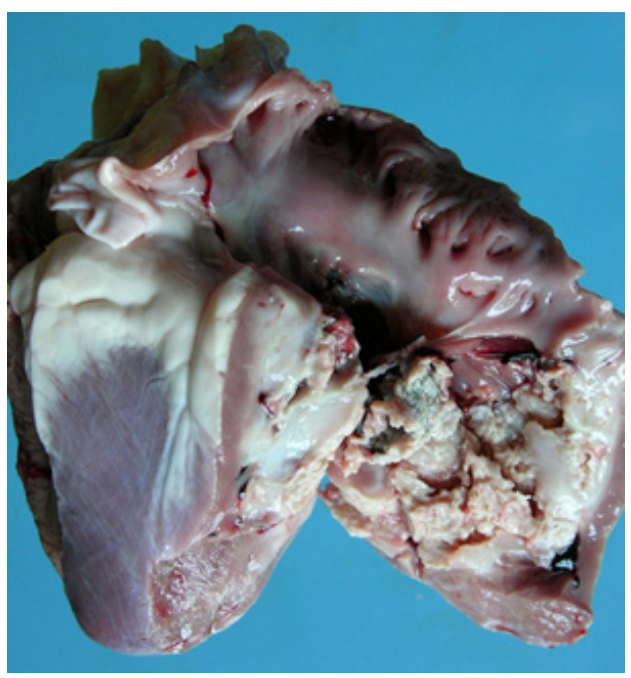

Figura 1. Endocardite mural e valvular por Arcanobacterium pyogenes em caprino. Material amarelado, irregular, vegetante sobre o endocárdio mural do ventrículo direito e na valva átrio ventricular direita.

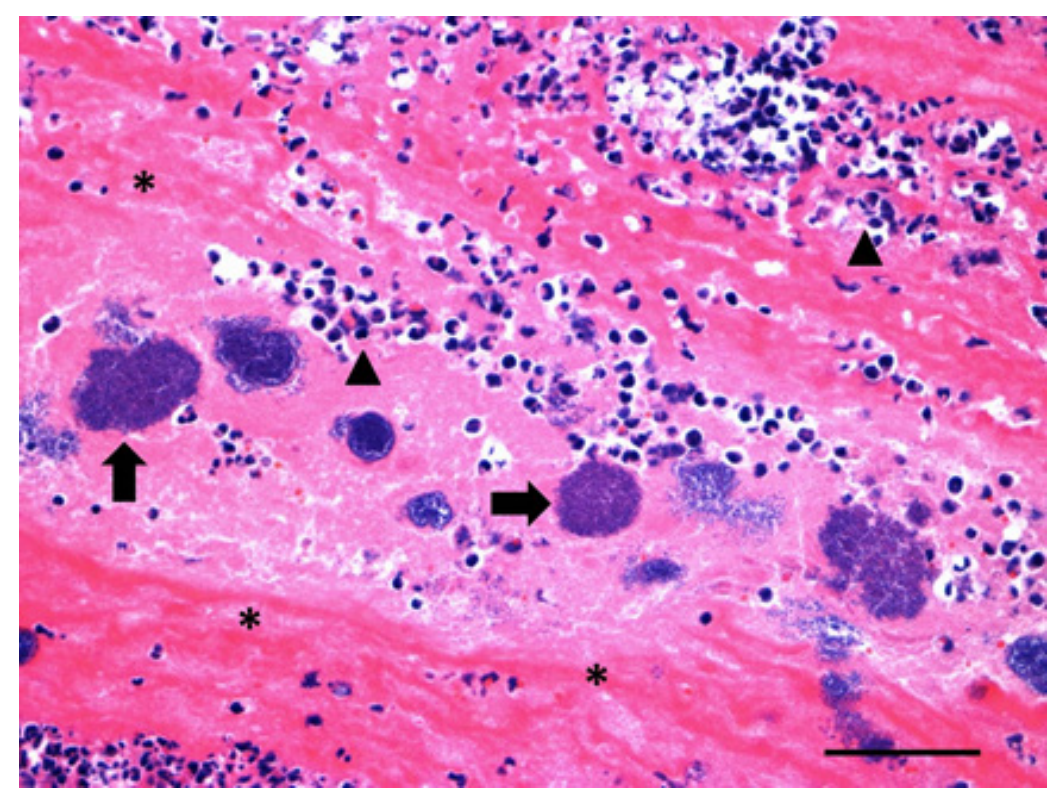

Figura 2. Endocardite por Arcanobacterium pyogenes. Miríades bacterianas (setas) em meio a abundante quantidade de fibrina (asterisco) e neutrófilos degenerados (cabeça de seta). HE, Bar 70 $\mu$ m.

Testes bioquímicos realizados em cultura pura incluíram catalase, redução de nitrato, hidrolise da gelatina, motilidade e produção de ácido a partir de ramnose. O microrganismo demonstrou habilidade de marcar o meio Loeffler em 48 horas sendo identificado como Arcanobacterium pyogenes (Quinn et al., 2011; Garino Junior et al., 2012).

Com base nos achados de necropsia, determinou-se que o animal foi acometido por uma pneumonia que evoluiu para uma septicemia e consequente endocartite de origem bacteriana, isto por que se isolou cultura pura de Arcanobacterium pyogenes das amostras de sangue, fígado e pulmão.

\section{Discussão}

Considerando que Pasteurella é o principal agente de pneumonias em caprinos, e que a maioria dos casos responde ao tratamento com oxitetraciclina (Belknap, 2004), este foi o antimicrobiano de escolha para tratamento dos sinais respiratórios. Como não foi observada resposta clínica adequada 
(Constable et al., 2010), após cinco dias foi iniciado tratamento com enrofloxacina e, embora esta fluoroquinolona seja um dos princípios ativos de última escolha nos casos de pneumonias em grandes ruminantes (Constable et al., 2010), entre as enfermidades do trato respiratório em caprinos encontram-se as causadas pelo gênero Mycoplasma (Oliveira et al., 2004) e as fluoroquinolonas são os antimicrobianos de eleição para estes casos ( Constable et al., 2010). Embora as descrições de micoplasmose caprina na Brasil datem de 1942, em surto de pleuropneumonia contagiosa - PPCC (Oliveira et al., 2004) esta enfermidade possui alta taxa de morbidade (Belknap, 2004) e, considerando que o rebanho era constituído por cerca de 350 animais e apenas um caprino apresentou manifestação de quadro clínico com sintomatologia respiratória, a PPCC seria desconsiderada no diagnóstico do presente caso. Entretanto, seu espectro de ação e resultados no tratamento de doenças respiratórias em caprinos levou à escolha deste medicamento, o qual já foi relatado como eficaz no tratamento de doenças respiratórias de ovinos (Viana et al., 2007).

O diagnóstico pós mortem, identificou o quadro como endocardite, que é a inflamação do endocárdio e pode apresentar lesões na aurícula e ventrículo (endocardite mural), mas as lesões são mais frequentemente observadas nas válvulas (endocardite valvular) (Smith et al., 1972).

O quadro clínico de endocardite é, inicialmente, assintomático e, a endocardite crônica, pode causar febre, anorexia e tosse e o método diagnóstico indicado para esta enfermidade é o exame cardiográfico (Cebra \& Cebra, 2004). Nesta enfermidade os sinais clínicos não são específicos o que dificulta o diagnóstico precoce. Além disso, o equipamento diagnóstico não faz parte da rotina clínica de campo para animais de produção. Desta forma, o prognóstico da endocardite bacteriana é reservado a desfavorável (Cebra \& Cebra, 2004).

Embora a endocardite seja comumente observada em animais adultos (Cebra \& Cebra, 2004), assim como no presente relato, em um ovino jovem (3 meses deidade) foi diagnosticado endocardite decorrente de infecção por Staphylococcus aureus (Waschburger et al., 2012). Esta enfermidade é, geralmente, de origem bacteriana e $A$. pyogenes é a espécie prevalente na enfermidade em bovinos (Bianco et al., 2004).

A. pyogenes é um habitante normal das membranas mucosas de animais domésticos como bovinos, ovinos, suínos e caprinos. Este microrganismo é um patógeno oportunista, causando uma variedade de infecções purulentas envolvendo pele, articulações, vísceras e órgãos. Embora capaz de agir como patógeno primário, a infecção por A. pyogenes comumente decorre de um processo infeccioso ou trauma prévio ao hospedeiro. Em caprinos, pode haver septicemia decorrente de um quadro clínico de pneumonia (Belknap, 2004). Entretanto, no presente relato, o quadro clínico de endocardite pode ter evoluído para um processo septicêmico, a partir do desprendimento de êmbolos sépticos (Traverso et al., 2003), semelhante à tromboembolia bacteriana observada por por A. pyogenes, em caprinos (Lin et al., 2010). Por outro lado, as lesões vegetativas se fragmentam com facilidade, resultando em partículas que podem originar abcessos em sítios distantes, como pulmões (Cebra \& Cebra, 2004). Embora nesse caso não tenha sido realizado antibiograma, o tratamento com antimicrobianos não determinou melhora clínica permanente, o que poderia estar associado à resistência do microrganismo (Santos et al., 2010; Giuffrida \& Bignarde, 2011), entre outros fatores.

As infecções por A. pyogenes são, geralmente, endógenas e, na maioria das espécies, causam abscessos nos tecidos. Em espécies de produção podem causar mastite crônica ou aguda, pneumonia supurativa, artrite séptica, endocardite vegetativa, endometrite, sinusite crônica, infecções umbilicais, vesiculite seminal e infecções secundárias em ferimentos (Quinn et al., 2011). Na espécie caprina, o envolvimento de $A$. pyogenes como patógeno oportunista em doença clínica tem sido documentado, sendo um dos agentes etiológicos mais importantes em infecções do trato reprodutivo e como agente secundário em infecções, com presença de lesões necróticas nos pulmões e abscessos no fígado e trato gastrointestinal (Barbour et al., 2010). A presença de lesões em múltiplos órgãos e presença de abscessos, relatados no presente caso, assemelha-se a quadros septicêmicos observados em caprinos jovens (Barbour et al., 2010; Lin et al., 2010) e como precursores de endocardites; assim como em ovelhas com retículo pericardite traumática, quando o agente foi isolado a partir de exsudato fibrino purulento e de abscessos no fígado, pulmões e baço (Torki et al., 2011).

Os critérios de identificação laboratorial de $A$. pyogenes utilizados no presente caso são aqueles relatados na literatura especializada (Quinn et al., 2011) e utilizados em casos clínicos 
em ruminantes (Guérin-Faublée et al., 1992). Embora a presença deste microrganismo pudesse ser atribuída à sua disseminação em decorrência do hiato entre morte e realização da necropsia ou mesmo à possível falta de refrigeração na propriedade de origem do caprino, o crescimento de cultura pura com ausência de outras espécies bacterianas, como E. coli, permite creditar o quadro observado ao microrganismo isolado.

\section{Conclusão}

Embora A. pyogenes seja usualmente associado a infecções localizadas, este relato ressalta seu envolvimento em doença septicêmica e acometimento do endocárdio na espécie caprina.

\section{Referências}

Barbour, E. K., Itani, H. H., Shaib, H. A., Saade, M. F., Sleiman, F. T., Nour, A. A., \& Harakeh, S. (2010). Koch's postulate of Arcanobacterium pyogenes and its immunigenecity in local and imported Saanen goats. Veterinaria Italiana, 46(3), 319-327. PMid:20857381.

Belknap, E. B. (2004). Enfermidades do Sistema respiratório. In Pugh D. G. (Ed.), Clínica de caprinos e ovinos (pp. 119-143). São Paulo: Roca.

Bianco, P., Capucchio, M. T., Catalano, D., Saracco, M., Dondo, A., Grattarola, C., \& Guarda, F. (2004). Endocardite ulcero-poliposa del bovino: indagine retrospettiva anatomo-patologica e bacteriológica. Large Animal Review, 10, 13-19.

Brasil, Ministério do Desenvolvimento, Indústria e Comércio, \& Associação Brasileira de Criadores de Ovinos (Org.). (2010). Estudo de mercado externo de produtos derivados da ovinocaprinocultura (166 p.). Passo Fundo: Méritos.

Cebra, C., \& Cebra, M. (2004). Enfermidades do Sistema cardiovascular. In Pugh D. G. (Ed.), Clínica de caprinos e ovinos (pp. 441-454). São Paulo: Roca.

Constable, P. D., Pyorala, S., \& Smith, G. W. (2010). Orientações para o uso de antimicrobianos em bovinos In L. Guardabassi, L. B. Jensen \& H. Kruse (Eds.), Guia de antimicrobianos em veterinária (pp. 180-199). Porto Alegre: Artmed.

Contreras, A., Luengo, C., Sánchez, A., \& Corrales, J. C. (2003). The role of intramammary pathogens in dairy goats. Livestock Production Science, 79(2-3), 273-283. http://dx.doi.org/10.1016/S0301-6226(02)00172-0.

Garino Junior, F., Matos, R. A. T., Miranda Neto, E. G., Bernardino, J. N. N., Santos, E. D., \& Aguiar, G. M. N. (2012). Mastite clínica caprina causada por Arcanobacterium pyogenes. Arquivo Brasileiro de Medicina Veterinária e Zootecnia, 64(4), 1070-1073. http://dx.doi.org/10.1590/S0102-09352012000400038.

Giuffrida, R., \& Bignarde, P. C. (2011). Perfil de sensibilidade microbiana in vitro de linhagens de Arcanobacterium pyogenes isoladas de diferentes afecções em bovinos. Veterinária e Zootecnia, 18, 222-225.

Guedes, K. M. R., Riet-Correa, F., Dantas, A. F. M., Simões, S. V. D., Miranda Neto, E. G., Nobre, V. M. T., \& Medeiros, R. M. T. (2007). Doenças do sistema nervoso central em caprinos e ovinos no semi-árido. Pesquisa Veterinária Brasileira, 27(1), 29-38. http://dx.doi.org/10.1590/S0100-736X2007000100006.

Guérin-Faublée, V., Karray, S., Tilly, B., \& Richard, Y. (1992). Actinomyces pyogenes: conventional and API system bacteriologic study of 103 strains isolated from ruminants. Annals of Veterinary Research, 23(2), 151-160. PMid:1610079.

Instituto Brasileiro de Geografia e Estatísitica - IBGE. (2006). Efetivos bubalinos, caprinos e ovinos de 1970 a 2006. Rio de Janeiro: IBGE. Recuperado em 5 de outubro de 2015, de http://www.ibge.gov.br/home/estatistica/ economia/agropecuaria/censoagro/2006/bubalino_e_suinos.pdf

Instituto Brasileiro de Geografia e Estatísitica - IBGE. (2010). Efetivo de caprinos em 31 de dezembro de 2010. Rio de Janeiro: IBGE. Recuperado em 5 de outubro de 2015, de http://www.ibge.gov.br/home/estatistica/ economia/ppm/2010/tabelas_pdf/tab16.pdf

Jost, B. H., \& Billington, S. J. (2005). Arcanobacterium pyogenes: molecular pathogenesis of an animal opportunist. Antonie van Leeuwenhoek, 88(2), 87-102. PMid:16096685.

Lavin, S., Marco, I., Franch, J., \& Abarca, L. (1998). Report of a case of pyogenic arthritis associated with Actinomyces pyogenes in a chamois (Rupricapra pyrenaica). Zentralblatt fur Veterinarmedizin. Reibe B, 45(4), 251-253. PMid:9640106.

Lin, C. C., Chen, T. H., Shyu, C. L., Su, N. Y., \& Chan, P. W. (2010). Disseminated abscessation complicated with bone marrow abscess caused by Arcanobacterium pyogenes in a goat. The Journal of Veterinary Medical Science, 72(8), 1089-1092. http://dx.doi.org/10.1292/jvms.09-0540. PMid:20467209.

Moeller Junior, R. B. (2001). Causes of caprine abortion: diagnostic assessment of 211 cases (1991-1998). Journal of Veterinary Diagnostic Investigation, 13(3), 265-270. http://dx.doi.org/10.1177/104063870101300317. PMid:11482610.

Oliveira, A. A. F., Alves, F. S. F., Pinheiro, R. R., \& Chapaval, L. (2004). Micoplasmoses em pequenos ruminantes (29 p.). Sobral: Embrapa Caprinos.

Pugh, D. G. (2005). Clínica de caprinos e ovinos (513 p.). São Paulo: Roca. 
Quinn, P. J., Markey, B. K., Leonard, F. C., Hartigan, P., Fanning, S., \& Fitzpatrick, E. S. (2011). Veterinary microbiology and microbial diseases (2nd ed., 912 p.). Oxford: Wiley Blackwell.

Rosa, F. B. (2012). Doenças de caprinos na região Central do Rio Grande do Sul (Dissertação de mestrado). Universidade Federal de Santa Maria, Santa Maria.

Santos, L. R., Scalco Neto, J. F., Rizzo, N. N., Bastiani, P. V., Rodrigues, L. B., Barcellos, H. H. A., \& Brun, M. V. (2010). Contaminação ambiental em um hospital veterinário e perfil de suscetibilidade a antimicrobianos das bactérias isoladas. Ciência Animal Brasileira, 11(2), 384-389. http://dx.doi.org/10.5216/cab.v11i2.2988.

Seifi, H. A., Saifzadeh, S., Farshid, A. A., Rad, M., \& Farrokhi, F. (2003). Mandibular pyogranulomatous osteomyelitis in a Saanen goat. Journal of Veterinary Medicine Series A, 5O(4), 219-221. http://dx.doi.org/10.1046/j.14390442.2003.00520.x. PMid:12948160.

Smith, H. A., Jones, T. C., \& Hunt, R. D. (1972). The cardiovascular system. In H.A. Smith, T. C. Jones \& R. D. Hunt (Ed.), Veterinary pathology (4th ed., pp. 1129-1166). Philadelphia: Lea \& Fabiger.

Thomson, R. G. (1983). Patologia geral veterinária. (412 p.). Rio de Janeiro: Guanabara Koogan.

Torki, E., Dezfoli, M. R. M., Sasani, F., Baghban, F., Shahabi, M., \& Motaghinejad, M. (2011). Traumatic reticulopericarditis (TRP) in sheep: a report of 4 cases in a herd. Slovenian Veterinary Research, 48(2), 45-50.

Traverso, S. D., Cunha, L., Fernandes, J. C. T., Loretti, A. P., Rhoden, A., Wunder Junior, E., \& Driemeier, D. (2003) Mastite com lesões sistêmicas por Staphylococcus aureus subesp. aureus em coelhos. Ciência Rural, 33(2), 373-376. http://dx.doi.org/10.1590/S0103-84782003000200031.

Ventura, F. V.C., \& Oliveira, S. T. (2011). Etiologia e terapia das endocardites bacterianas em cães - revisão. Arquivos de Ciências Veterinárias e Zoologia da UNIPAR, 14, 145-150.

Viana, L., Gonçalves, R. C., Oliveira Filho, J. P., Paes, A. C., Chiacchio, S. B., \& Ribeiro, M. G. (2007). Susceptibilidade in vitro a antimicrobianos da Mannheimia haemolytica e da Pasteurella multocida isoladas de ovinos sadios e com doenças respiratórias. Brazilian Journal of Veterinary Research and Animal Science, 44(supl.), 111-114. http://dx.doi.org/10.11606/issn.1678-4456.bjvras.2007.26598.

Waschburger, D. J., Gonçalves, M. A., Krabbe, A., Lübeck, I., \& Anjos, B. L. (2012). Endocardite e arterite valvular estafilocócica em um ovino. Arquivos de Pesquisa Animal, 1, 1-7. 